\title{
Effect of population screening for type 2 diabetes and cardiovascular risk factors on mortality rate and cardiovascular events: a controlled trial among 1,912,392 Danish adults
}

\author{
Rebecca K. Simmons ${ }^{1,2,3,4,5}$ • Simon J. Griffin ${ }^{1,3,6} \cdot$ Daniel R. Witte $^{4,7}$ • \\ Knut Borch-Johnsen $^{8}$ • Torsten Lauritzen ${ }^{3}$ - Annelli Sandbæk ${ }^{3}$
}

Received: 3 March 2017 / Accepted: 10 May 2017 /Published online: 23 August 2017

(C) The Author(s) 2017. This article is an open access publication

\begin{abstract}
Aims/hypothesis Health check programmes for chronic disease have been introduced in a number of countries. However, there are few trials assessing the benefits and harms of these screening programmes at the population level. In a post hoc analysis, we evaluated the effect of population-based screening for type 2 diabetes and cardiovascular risk factors on mortality rates and cardiovascular events.

Methods This register-based, non-randomised, controlled trial included men and women aged 40-69 years without known diabetes who were registered with a general practice in Denmark $(n=1,912,392)$. Between 2001 and 2006, 153,107
\end{abstract}

Electronic supplementary material The online version of this article (doi:10.1007/s00125-017-4323-2) contains peer-reviewed but unedited supplementary material, which is available to authorised users.

Rebecca K. Simmons

rks34@cam.ac.uk

1 MRC Epidemiology Unit, University of Cambridge School of Clinical Medicine, Box 285, Institute of Metabolic Science, Cambridge Biomedical Campus, Cambridge CB2 0QQ, UK

2 Steno Diabetes Center, Gentofte, Denmark

3 Department of Public Health, Section of General Practice, Aarhus University, Aarhus, Denmark

4 Danish Diabetes Academy, Odense University Hospital, Odense, Denmark

5 Aarhus Institute of Advanced Studies, Aarhus, Denmark

6 Primary Care Unit, Institute of Public Health, University of Cambridge, Cambridge, UK

7 Department of Public Health, Section of Epidemiology, Aarhus University, Aarhus, Denmark

8 Holbæk Hospital, Holbæk, Denmark individuals registered with 181 practices participating in the Anglo-Danish-Dutch Study of Intensive Treatment in People with Screen-Detected Diabetes in Primary Care (ADDITION)Denmark study were sent a diabetes risk score questionnaire. Individuals at moderate-to-high risk were invited to visit their GP for assessment of diabetes status and cardiovascular risk (screening group). The 1,759,285 individuals registered with all other general practices in Denmark constituted the retrospectively constructed no-screening (control) group. Outcomes were mortality rate and cardiovascular events (cardiovascular disease death, non-fatal ischaemic heart disease or stroke). The analysis was performed according to the intention-to-screen principle. Results Among the screening group, 27,177 (18\%) individuals attended for assessment of diabetes status and cardiovascular risk. Of these, 1,533 were diagnosed with diabetes. During a median follow-up of 9.5 years, there were 11,826 deaths in the screening group and 141,719 in the no-screening group (HR 0.99 [95\% CI 0.96, 1.02], $p=0.66$ ). There were 17,941 cardiovascular events in the screening group and 208,476 in the no-screening group (HR 0.99 [0.96, 1.02], $p=0.49$ ).

Conclusions/interpretation A population-based stepwise screening programme for type 2 diabetes and cardiovascular risk factors among all middle-aged adults in Denmark was not associated with a reduction in rate of mortality or cardiovascular events between 2001 and 2012.

Keywords Cardiovascular disease - General practice . Mortality rate · Population · Screening · Type 2 diabetes

\footnotetext{
Abbreviations

ADDITION Anglo-Danish-Dutch study of intensive treatment in people with screen-detected diabetes in primary care
} 


$\begin{array}{ll}\text { CVD } & \text { Cardiovascular disease } \\ \text { FBG } & \text { Fasting blood glucose } \\ \text { GP } & \text { General practitioner } \\ \text { IFG } & \text { Impaired fasting glucose } \\ \text { IGT } & \text { Impaired glucose tolerance } \\ \text { IHD } & \text { Ischaemic heart disease } \\ \text { RBG } & \text { Random blood glucose }\end{array}$

\section{Introduction}

As governments seek to apply the principles of prevention to chronic disease, health check programmes have been proposed or introduced in a number of countries, including the UK and the USA [1,2]. These usually include assessment and management of risk factors for chronic disease, most of which are related to cardiovascular disease (CVD). Modelling studies suggest that screening for diabetes and cardiovascular risk assessment might be both effective and cost-effective; however, these studies rely on a number of assumptions [3-7]. There are relatively few trials assessing the benefits and harms of screening at the population level $[8,9]$. A Cochrane review of randomised trials comparing health checks with no health checks in adult populations found that they did not reduce morbidity, all-cause mortality or cardiovascular-related mortality rates, although the number of new diagnoses increased [10]. The review included data from a number of historical cohorts that were initiated before the widespread introduction of effective treatments such as statins. More recent studies examining the impact of systematic population-wide screening have shown mixed results. INTER-99 reported no effect and the Västerbotten Intervention Programme, which combined screening with a wider public health promotion programme, reported mortality rate reductions $[9,11]$.

Given the limited evidence of the impact of populationbased screening programmes, it is important to explore whether health checks might have different impacts in contemporary populations. It is also critical to evaluate the impact of screening on overall population mortality rates rather than simply disease-specific mortality or disease event rates to quantify overall benefits and harms at the population level [12]. Between 2001 and 2006, a population-based cardiovascular risk assessment and diabetes screening programme was introduced in five Danish counties as part of the Anglo-DanishDutch Study of Intensive Treatment in People with ScreenDetected Diabetes in Primary Care (ADDITION) study [13]. The Danish national registration system enables a post hoc analysis of the rates of mortality and cardiovascular events in individuals who were invited to take part in the ADDITION-Denmark screening programme compared with individuals who were not invited during the same time period.

\section{Methods}

ADDITION-Denmark consists of two phases: a pragmatic screening programme; and a cluster-randomised trial comparing the effects of intensive multifactorial therapy with routine care among individuals with screen-detected type 2 diabetes $[13,14]$. We report results from a post hoc analysis of data from the screening phase of the study in conjunction with outcome data from Danish national registers. Ethical approval for the ADDITION-Denmark study was granted by a local scientific committee (no: 20000183). As this was a registrybased study using anonymised data, participants did not give informed consent. This approach was approved by the Danish Data Protection Agency and the Danish Health and Medicine Authority.

Intervention We performed a population-based stepwise screening programme among people aged 40-69 years without known diabetes between 2001 and 2006. Full details have been published previously [13-15]. All general practices in five out of 16 counties in Denmark (Copenhagen, Aarhus, Ringkøbing, Ribe and South Jutland) were invited to take part in ADDITION-Denmark ( $n=744) ; 209$ (28.1\%) accepted (county-specific proportions ranged from 21 to $37 \%$ ). Eligible individuals aged 40-69 years without diagnosed diabetes who were registered with 181 general practices that were part of the study were sent a diabetes risk score questionnaire $[14,15]$. Individuals who scored $\geq 5$ points (maximum 15 points) were invited to visit their general practitioner (GP) for a diabetes test and a cardiovascular risk assessment. The risk score was developed using the Danish Inter99 population [15]. The sensitivity and specificity for predicting undiagnosed diabetes are 68.9-77.0\% and 68.8-78\%, respectively, using four different cut-off points [15]. External validation using the chosen cut-off point of $\geq 5$ was completed using data from 1028 individuals in a pilot for the ADDITION study and revealed a sensitivity of $76.0 \%$ (95\% CI 58.3, 90.3) and specificity of $72.2 \%(69.3,75.1)$ for diabetes. In Aarhus and Copenhagen counties, 35 practices also completed opportunistic screening, in which individuals were asked to complete the risk score questionnaire when attending the practice for other reasons. Participants who attended a screening appointment underwent measurement of height, weight, BP, random blood glucose (RBG), total cholesterol and $\mathrm{HbA}_{1 \mathrm{c}}$. Participants also answered a question about their smoking status. GPs were encouraged to calculate the European Heart SCORE [16] during the appointment, to inform individuals about their score and provide appropriate advice to those at high risk. Individuals with an $\mathrm{RBG} \geq 5.5 \mathrm{mmol} / \mathrm{l}$ or $\mathrm{HbA}_{1 \mathrm{c}} \geq 5.8 \%(40 \mathrm{mmol} / \mathrm{mol})$ were invited to return to the practice for a fasting capillary blood glucose (FBG) test. An OGTT was performed at the same consultation if FBG was $5.6-6.1 \mathrm{mmol} / 1$ and/or $\mathrm{HbA}_{1 \mathrm{c}} \geq 5.8 \%$. GPs were notified of all results. The WHO 
1999 criteria were used to diagnose diabetes [17], including the requirement for a confirmatory test on another day.

Participants diagnosed with type 2 diabetes were subsequently managed according to the treatment regimen to which their practice had been allocated: routine care or intensive treatment [18]. For individuals found to have impaired fasting glucose (IFG) or impaired glucose tolerance (IGT) [17], and/ or a high CVD risk (SCORE $>5$ points), practitioners were encouraged to manage cardiovascular risk factors according to national guidelines [19], including annual cardiovascular risk assessment and diabetes tests.

In order to assess the impact of invitation to screening on population mortality rates, all individuals in the original ADDITION-Denmark sampling frame ( $n=153,107)$, including those who did not attend for screening, were identified on the Danish National Registry system (the screening group). Using the same registry, we also identified all individuals aged 40-69 years without known diabetes who, between 2001 and 2006, were registered with general practices that were not invited or who declined to take part in ADDITIONDenmark ( $n=1,759,285$ ) (the no-screening group) (Fig. 1). We linked information about these individuals to other Danish registers using unique civil registration numbers. We retrieved information on age, sex, education, region, immigration/emigration, citizenship, redeemed cardioprotective medication and chronic disease (ischaemic heart disease [IHD], stroke, cancer). Education was categorised according to UNESCO's International Standard Classification of Education [20]. We grouped data on citizenship into European and nonEuropean citizens as a proxy for ethnicity.

Outcomes Participants were followed for a median of 9.5 years to 31 December 2012, when national registers were searched for information on vital status and incident CVD events. For death, the primary outcome was all-cause mortality rate (based on underlying cause of death). Secondary outcomes were cardiovascular-, cancer- and diabetes-related mortality rates. Cause-specific deaths were coded blind to study group using ICD-10 codes (www.who.int/classifications/icd/ en/; electronic supplementary material (ESM) Table 1). For CVD, the primary outcome was a composite of first event of cardiovascular death, non-fatal IHD (ICD-10 codes I20-I25 and I46) or non-fatal stroke (ICD-10 code I6*). Data on incident CVD events was gathered from the National Patient Registry, which records all inpatient and outpatient hospitalisations in Denmark.

Statistical analysis Analysis was by intention-to-screen at the population level comparing outcomes in people registered at screening practices with those registered at no-screening practices. All eligible participants were considered irrespective of their participation in the screening programme. Baseline characteristics were summarised separately in the screening and no-screening (control) groups using the unpaired $t$ test for continuous data and $\chi^{2}$ test for categorical data. Date of entry to the study for individuals in the screening practices was the date of invitation to screening. Date of entry for the noscreening (control) practices was the mid-point (29 June 2003) of the randomisation period of ADDITIONDenmark practices (2001-2006). Individuals were censored on the date of first event, date of emigration or 31 December 2012, whichever was earliest. HRs comparing mortality rates and CVD outcomes between the screening and no-screening groups were estimated using a Cox proportional hazards regression model. As allocation to screening in ADDITIONDenmark was at the practice level, robust standard errors were calculated that take into account the two-level structure of the data (individuals clustered within practices) [21] and any potential correlation between individuals within practices. We adjusted for age, sex, education and prevalent chronic disease (IHD, stroke, cancer). To further account for differences in social structure, we stratified the baseline hazards by county. We also compared outcomes between screening attenders with the no-screening group. Attendance was defined as attending the initial consultation for diabetes testing and CVD risk assessment. To assess possible bias from unknown antecedent disease, sensitivity analyses were conducted omitting deaths from both groups occurring within 1 year of randomisation ( $n=12,375$ ). We also re-ran the Cox model comparing mortality outcomes after excluding individuals affiliated to general practices undertaking opportunistic screening. We calculated the proportion of participants who redeemed prescriptions for lipid-lowering, anti-hypertensive and glucose-lowering medication from 2000 to 2008 in both groups. All analyses were completed using Stata version 14.1 (STATA, College Station, Texas, USA).

\section{Results}

The screening and control groups were well balanced for age, sex and citizenship at baseline (Table 1). Compared with the control group, a larger proportion of the screening group (330,096 [19.3\%] vs 34,648 [23.1\%]) had received $>15$ years of education. Slightly higher proportions of the control group had experienced IHD, stroke or cancer compared with the screening group.

Of 153,107 eligible people in the screening group, 27,177 (18\%) attended their GP for a diabetes test and a cardiovascular risk assessment. Of these, 1533 participants (1\% of those eligible for screening) were diagnosed with diabetes and 2526 $(1.6 \%)$ had IFG/IGT. Of all individuals who attended screening for ADDITION-Denmark with complete data for calculating CVD risk, 9693/20,223 (48\%) had high CVD risk (European Heart SCORE $\geq 5$ points). In total, 6855 (28\%) of attenders with available data reported being a current 
Fig. 1 ADDITION-Denmark screening flow

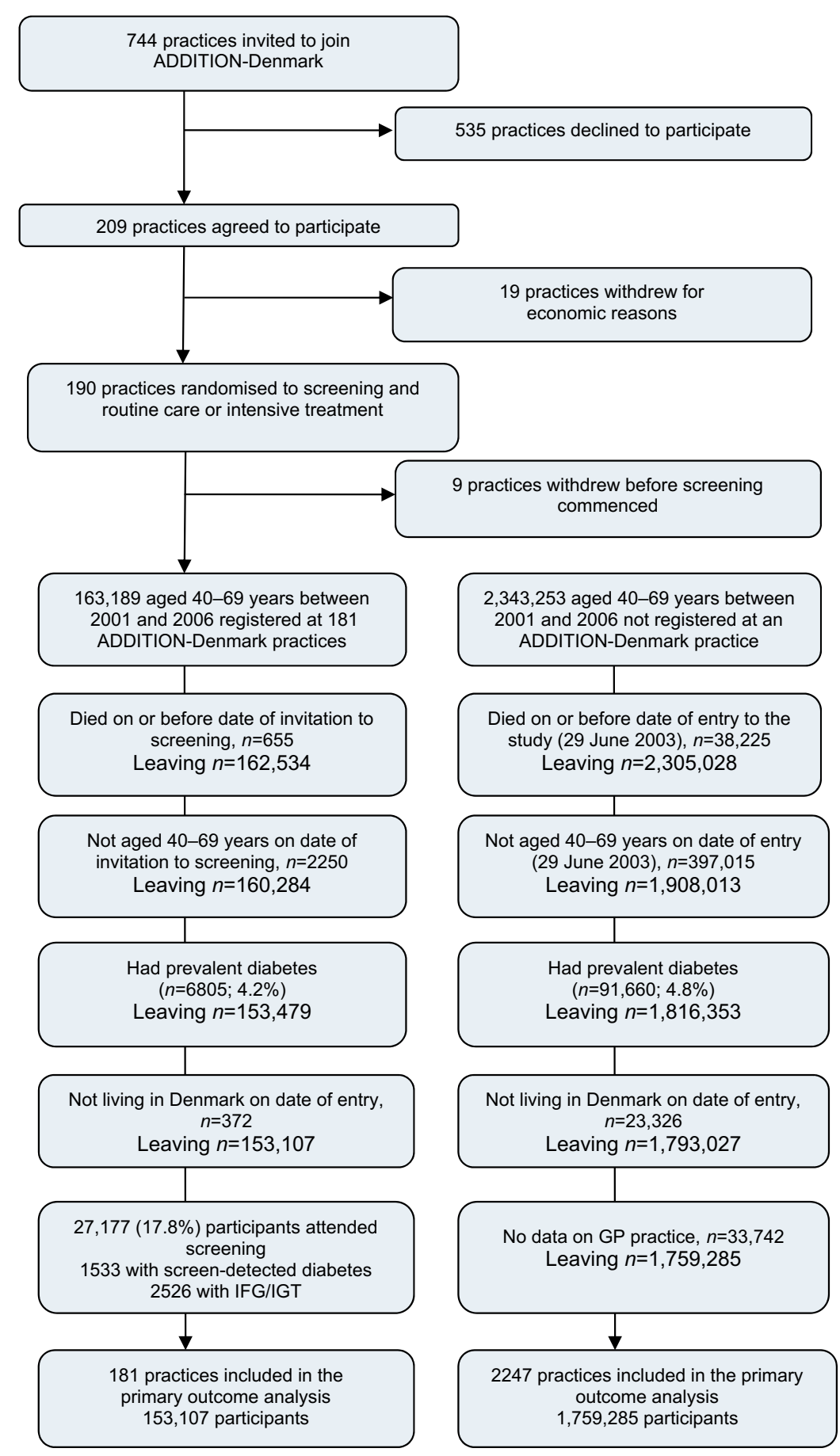

smoker. There were 1,759,285 individuals in the no-screening control group.

Effect of screening on mortality rate Median duration of follow-up was 9.5 years $(16,954,630$ person-years). During follow-up, there were 11,826 deaths in the screening group $(7.7 \%)$ and 141,719 in the no-screening control group $(8.1 \%)$ (Table 2$)$. The most common cause of death was cancer in the two groups $(n=67,694,44.5 \%)$. Following adjustment, there was no significant difference in the allcause mortality rate between the screening and the control groups (HR 0.99 [95\% CI 0.96, 1.02], $p=0.66$ ) (Table 2). Sensitivity analyses showed that the overall result was not affected by the exclusion of people who died within 1 year of the beginning of the study $(n=12,375 ; 0.99$ [0.96, 1.02], $p=0.60)$ or of individuals affiliated to general practices undertaking opportunistic screening (1.00 [0.97, 1.03], $p=0.93)$. Compared with the no-screening group, attending for 
Table 1 Baseline characteristics of participants in the screening and no-screening groups (20012006)

\begin{tabular}{lcc}
\hline Characteristic & $\begin{array}{c}\text { Screening group } \\
(n=153,107)\end{array}$ & $\begin{array}{c}\text { No-screening (control) } \\
\text { group }(n=1,759,285)\end{array}$ \\
\hline $\begin{array}{l}\text { Mean age (SD), years } \\
\text { Male sex, } n(\%)\end{array}$ & $53.6(8.1)$ & $53.4(8.2)$ \\
Years of education, $n(\%)^{\mathrm{a}}$ & $75,569(49.4)$ & $875,241(49.8)$ \\
$\quad 0-10$ & $46,232(30.8)$ & \\
$\quad 10-15$ & $69,025(46.1)$ & $571,727(33.4)$ \\
$\quad>15$ & $34,648(23.1)$ & $808,851(47.3)$ \\
European citizenship, $n(\%)^{\mathrm{a}}$ & $151,937(99.3)$ & $330,096(19.3)$ \\
Previous IHD ${ }^{\mathrm{b}}, n(\%)$ & $4989(3.3)$ & $1,738,603(99.0)$ \\
Previous stroke ${ }^{\mathrm{b}}, n(\%)$ & $2313(1.5)$ & $63,734(3.6)$ \\
Previous cancer $^{\mathrm{b}}, n(\%)$ & $15,210(9.9)$ & $29,023(1.7)$ \\
\hline
\end{tabular}

${ }^{\text {a }}$ Totals do not match denominator owing to missing data

${ }^{\mathrm{b}}$ Data taken from the National Patient Registry; data available from 1994 onwards screening was associated with a $25 \%$ reduction in risk of death $(0.75[0.71,0.78])$.

There was no significant difference between groups in cardiovascular mortality rate (HR 1.02 [95\% CI 0.96, 1.08], $p=0.60)$ and cancer mortality rate $(0.99$ [0.96, 1.03], $p=0.69$ ) (Table 2). Diabetes was listed anywhere on the death certificate for 981 individuals (77 in the screening group [0.7\%] and 904 in the control group [0.6\%]). There was no significant difference between groups in diabetes-related mortality rate $(1.10[0.84,1.44], p=0.51$; Table 2$)$.

Effect of screening on CVD Median duration of follow-up was 9.5 years $(16,499,722$ person-years). Following entry to the study, there were 17,941 first CVD events in the screening group (11.7\%) and 208,476 in the no-screening group (11.8\%) (HR 0.99 [95\% CI 0.96, 1.02], $p=0.49$ ) (Table 2). The composite CVD event included 12,552 CVD deaths, 138,809 non-fatal IHD and 75,057 non-fatal strokes.

Cardioprotective medication At baseline, the proportion of participants redeeming cardioprotective medication was similar in both groups (Table 3). Following commencement of the screening programme in 2001, larger numbers of people in the screening practices redeemed glucose-lowering medication compared with control practices (after excluding individuals with prevalent diabetes in each practice). This difference narrowed over time but was maintained until 2007, when both groups were prescribed similar levels of glucose-lowering medication $(30,824$ [1.81\%] in the no-screening group and 2769 [1.87\%] in the screening group). Similarly, larger numbers of people in the screening practices redeemed lipidlowering prescriptions compared with the control practices. Similar proportions of participants in both groups redeemed

Table 2 Incidence of all-cause and cardiovascular-, cancer- and diabetes-related mortality, and CVD events, by screening group (2001-2012)

\begin{tabular}{|c|c|c|c|c|c|c|c|}
\hline \multirow[t]{2}{*}{ Variable } & \multicolumn{3}{|c|}{ Screening group $(n=153,107)$} & \multicolumn{3}{|c|}{ No-screening group ( $n=1,759,285)$} & \multirow{2}{*}{$\begin{array}{l}\text { Adjusted HR } \mathrm{HR}^{\mathrm{a}} \\
(95 \% \mathrm{CI})\end{array}$} \\
\hline & $\begin{array}{l}\text { Number } \\
\text { of events }\end{array}$ & $\begin{array}{l}\text { Person-years } \\
\text { of follow-up }\end{array}$ & $\begin{array}{l}\text { Rate per } 1000 \\
\text { person-years } \\
(95 \% \mathrm{CI})\end{array}$ & $\begin{array}{l}\text { Number } \\
\text { of events }\end{array}$ & $\begin{array}{l}\text { Person-years } \\
\text { of follow-up }\end{array}$ & $\begin{array}{l}\text { Rate per } 1000 \\
\text { person-years } \\
(95 \% \mathrm{CI})\end{array}$ & \\
\hline \multicolumn{8}{|l|}{ Mortality } \\
\hline All-cause & 11,826 & $1,425,981$ & $8.29(8.15,8.44)$ & 141,719 & $15,972,368$ & $8.87(8.83,8.92)$ & $0.99(0.96,1.02)$ \\
\hline Cardiovascular-related & 2291 & $1,425,981$ & $1.61(1.54,1.67)$ & 27,435 & $15,972,368$ & $1.72(1.70,1.74)$ & $1.02(0.96,1.08)$ \\
\hline Cancer-related & 5387 & $1,425,981$ & $3.78(3.68,3.88)$ & 62,307 & $15,972,368$ & $3.90(3.87,3.93)$ & $0.99(0.96,1.03)$ \\
\hline Diabetes-related $^{\mathrm{b}}$ & 74 & $1,425,981$ & $0.05(0.04,0.07)$ & 904 & $15,972,368$ & $0.06(0.05,0.06)$ & $1.10(0.84,1.44)$ \\
\hline Composite cardiovascular event ${ }^{\mathrm{c}}$ & 17,941 & $1,352,463$ & $13.28(13.08,13.47)$ & 208,476 & $15,148,258$ & $13.76(13.70,13.82)$ & $0.99(0.96,1.02)$ \\
\hline
\end{tabular}

${ }^{\text {a }} \mathrm{HR}$ was estimated with a Cox proportional hazards regression model. Robust SEs were calculated taking into account the two-level structure of the data and any potential correlation between individuals within practices. Models were adjusted for age, sex, education and prevalent chronic disease (IHD, stroke, cancer); baseline hazards were stratified by county

${ }^{\mathrm{b}}$ Diabetes-related mortality includes any death with an ICD-10 code E10* to E14*

${ }^{\mathrm{c}}$ First of CVD death, non-fatal IHD or non-fatal stroke 
Table 3 Redeemed cardioprotective medication from 2000 to 2008

\begin{tabular}{|c|c|c|c|c|c|c|c|c|c|}
\hline \multirow[t]{2}{*}{ Year $^{\mathrm{a}}$} & \multicolumn{3}{|c|}{ Glucose-lowering medication } & \multicolumn{3}{|c|}{ Lipid-lowering medication } & \multicolumn{3}{|c|}{ Anti-hypertensive medication } \\
\hline & Screening & No-screening & $p$ value & Screening & No-screening & $p$ value & Screening & No-screening & $p$ value \\
\hline 2000 & $14(0.01)$ & $215(0.01)$ & 0.29 & $3137(2.1)$ & $36,286(2.1)$ & 0.72 & $20,629(13.5)$ & $241,916(13.8)$ & 0.0025 \\
\hline 2001 & $83(0.05)$ & $188(0.01)$ & $<0.0001$ & $3921(2.56)$ & $45,443(2.58)$ & 0.63 & 23,097 (15.09) & $268,441(15.26)$ & 0.086 \\
\hline 2002 & $275(0.18)$ & $219(0.01)$ & $<0.0001$ & $5402(3.54)$ & $59,709(3.39)$ & 0.0030 & $25,884(16.95)$ & $298,665(16.98)$ & 0.79 \\
\hline 2003 & $666(0.44)$ & $3373(0.19)$ & $<0.0001$ & $7836(5.15)$ & $82,590(4.71)$ & $<0.0001$ & $29,087(19.13)$ & $333,731(19.03)$ & 0.34 \\
\hline 2004 & $1103(0.73)$ & $9652(0.55)$ & $<0.0001$ & $10,974(7.26)$ & $114,726(6.59)$ & $<0.0001$ & $32,117(21.24)$ & $371,711(21.34)$ & 0.35 \\
\hline 2005 & $1567(1.04)$ & $15,899(0.92)$ & $<0.0001$ & $13,712(9.12)$ & $148,728(8.60)$ & $<0.0001$ & $35,286(23.47)$ & $407,319(23.55)$ & 0.50 \\
\hline 2006 & $2119(1.42)$ & $22,810(1.33)$ & 0.0036 & $17,116(11.47)$ & $191,917(11.18)$ & 0.0010 & $38,826(26.01)$ & $446,981(26.05)$ & 0.74 \\
\hline 2007 & 2769 (1.87) & $30,824(1.81)$ & 0.11 & $21,029(14.20)$ & $236,299(13.89)$ & 0.0011 & 42,207 (28.49) & $485,665(28.55)$ & 0.66 \\
\hline 2008 & $3490(2.38)$ & $40,117(2.38)$ & 0.93 & $25,034(17.04)$ & $284,675(16.88)$ & 0.12 & $45,454(30.94)$ & $522,555(30.99)$ & 0.69 \\
\hline
\end{tabular}

Data are presented as $n(\%)$

ATC codes: glucose-lowering medication $\left(\mathrm{A}^{*}\right)$; lipid-lowering medication $\left(\mathrm{C} 10^{*}\right)$; anti-hypertensive medication $\left(\mathrm{CO} 7^{*}, \mathrm{CO} 8^{*}, \mathrm{C} 09^{*}\right)$

${ }^{a}$ Denominator population based on participants who were alive on 1 January for each year

prescriptions for anti-hypertensive medication throughout the follow-up period.

\section{Discussion}

In this population-based sample of nearly two million middleaged Danish adults, a single round of screening for type 2 diabetes and cardiovascular risk assessment was not associated with a reduction in the rates of all-cause mortality or cardiovascular events between 2001 and 2012. Similarly, rates of cardiovascular-, cancer- and diabetes-related mortality were not reduced by invitation to screening.

Modelling studies have previously suggested a benefit of population screening for diabetes and related risk factors for vascular disease [3-7]. This finding was supported by examination of the Ely cohort [22], in which individuals aged 40-65 years who were invited to diabetes screening every 5 years between 1990 and 1999 had a non-significant $21 \%$ lower all-cause mortality rate than individuals who were not invited to screening; however, this finding was not replicated in between 2000 and 2008.

A more recent screening and health promotion CVD intervention undertaken in Västerbotten County, Sweden, also showed a significant long-term reduction in all-cause and CVD mortality rates when compared with the general Swedish population [11]. This complex intervention was different from the ADDITION-Denmark study. The screening programme and health counselling offered to individuals was nested within a public health prevention programme targeting the wider collective determinants of diabetes and CVD. However, our findings mirror those of a pragmatic, parallel-group, cluster-randomised trial in 33 general practices in eastern England (ADDITION-Cambridge) [8], in which screening for type 2 diabetes in those at high risk did not result in a reduction in all-cause or cardiovascular- or diabetesrelated mortality rates over 10 years. Our results also reaffirm a recent Cochrane review [10], which found no long-term impact of general health checks on mortality and morbidity rates following population screening.

There are many potential explanations for the lack of difference in mortality rates and cardiovascular events observed in this trial. The study was undertaken against a background of national interest about screening and early treatment for diabetes in Denmark. The effect of screening may therefore have been diluted by opportunistic screening in primary care and by continuing improvement in the detection and management of CVD risk factors. Only 27,177 (18\%) of individuals in the screening group attended their general practice for testing which combined with the less than $100 \%$ sensitivity at each step of the screening programme might have contributed to the low yield of individuals found to have detectable disease (1\% of the invited population) [14]. Although earlier detection may have benefitted those diagnosed with diabetes [18], the proportion was probably too small to affect population mortality rates. Furthermore, screening attendees are frequently those at lowest risk [23].

For cancers such as prostate, any effect of screening on population mortality rates is achieved largely through the effect of treatment in the lead time between detection by screening and clinical diagnosis [24]. By contrast, CVD risk factor screening identifies a significant proportion of the population that might benefit from health promotion and lifestyle change, which could also impact other health outcomes such as cancer. Unlike the ADDITION-Cambridge trial, the Danish screening programme included assessment of CVD risk factors alongside screening for undiagnosed prevalent diabetes. This is similar to recommendations in the UK NHS Health Checks Programme 
[1]. Danish GPs were encouraged to intervene in individuals with IFG/IGT and those with high CVD risk but without diagnosed diabetes. While small numbers of individuals were diagnosed with diabetes following screening in Denmark (1\%), $1.6 \%$ were found with IFG/IGT and $48 \%$ with elevated cardiovascular risk (SCORE > 5 points), providing a larger at-risk group with the potential to benefit from interventions to prevent both diabetes and CVD $[25,26]$. Indeed, larger proportions of people in the screening practices redeemed cardioprotective medication compared with the control practices during the screening phase of the study (2001-2006). However, these differences were small and were not sustained. Furthermore, there is evidence of sub-optimal treatment among individuals identified at high risk in health check programmes [27] and among those with screen-detected diabetes [18], which might have contributed to the lack of difference between groups. Indeed, follow-up of ADDITION-Denmark participants who did not have diabetes but had high CVD risk and dyslipidaemia showed that only $20 \%$ were started on lipid-lowering treatment following screening [28]. Of these, only 53\% reached the treatment goal of total cholesterol $<5.0 \mathrm{mmol} / 1$ and LDL-cholesterol $<3 \mathrm{mmol} / \mathrm{l}$ within 1 year of starting treatment [29]. Among those with screen-detected diabetes, there was wide variation between general practices in prescription of lipid-lowering treatment [30]. As such, there is evidence of both undertreatment and considerable delay in starting treating among this high-risk population. Benefits to the population might have been increased by identification of non-attenders, targeting of screening to those at greatest risk, strategies to maximise uptake of screening (particularly among those at highest risk), repeated rounds of screening and optimal treatment of detected disease. Benefits might also be increased by introducing complex interventions that target collective determinants of chronic disease alongside individualised screening and treatment programmes. For example, the Västerbotten Intervention Programme aimed to raise public awareness of CVD risk factors and lifestyle behaviours by tailoring activities to the local community, including the introduction of 'the green keyhole' food labelling system denoting low fat and high fibre foods, development of healthy school lunches, production and distribution of health educational materials, and health information meetings [11]. Participation rates in Västerbotten were 48-67\%. Our results underline the continuing uncertainty about the overall benefits of population screening for diabetes and CVD.

As with all screening programmes, positive health outcomes are associated with uptake. In common with findings from other population-based screening programmes, we observed the lowest mortality rates in attenders, probably due, at least in part, to healthy volunteer bias.

Strengths and limitations This very large non-randomised, controlled trial with 9.5 years of follow-up included all individuals aged 40-69 years without diagnosed diabetes in
Denmark between 2001 and 2006. Outcome ascertainment was robust. The National Death Registry estimates $100 \%$ coverage of mortality based on death certificates. All-cause mortality is an all-inclusive measure that addresses both direct and indirect benefits and harms of screening, and puts diseasespecific mortality rate reduction in the context of other competing risks [12]. We were able to ascertain which individuals were living in Denmark during the screening period and those who emigrated during follow-up. Deaths and CVD events were coded blind to study group. We used a validated risk score developed and evaluated in a Danish population to identify those at high risk of undiagnosed diabetes [15].

A limitation of our study includes the post hoc, nonrandomised design, which means that we cannot eliminate the possibility of selection bias and residual confounding. Groups were well balanced for most baseline characteristics. However, there were higher levels of education and slightly lower levels of pre-existing chronic disease in the screening compared with the no-screening group. These differences would have tended to increase the apparent benefits of screening. In order to minimise the impact of these small baseline differences between study groups, we adjusted for age, sex, education and prevalent chronic disease at the individual level. We also accounted for clustering and stratified the baseline hazard function by county to allow for potential baseline differences in underlying determinants of disease by geographical region.

In terms of practice characteristics, data were not available with which to compare the screening and no-screening groups. The small differences at baseline between study groups suggest that practices participating in ADDITIONDemark served less deprived regions than the average Danish practice. The benefits of screening might be greater among more socioeconomically deprived communities in which the absolute disease risk is higher, although attendance for screening is likely to be lower [23]. The vast majority of participants were white European, the main ethnic group in Denmark, which also limits generalisability to other settings. We did not measure the potential psychological harms of screening for diabetes and related cardiovascular risk factors and subsequent treatment in ADDITION-Denmark. However, previous research suggests that such adverse effects are limited in both the short and longer term [31, 32].

While we were able to compare trends in redeemed cardioprotective medication to explore a potential effect of the screening programme, it would also have been useful to examine diet, physical activity and smoking behaviour. However, these data are not available for the entire Danish population. One-third of the individuals diagnosed with diabetes by screening in ADDITION-Denmark reported that they had stopped smoking by five-year follow-up. Furthermore the cohort lost an average of $2 \mathrm{~kg}$ in weight [18]. These behavioural responses further suggest that detection of diabetes by 
screening was associated with a positive impact among those found to have undiagnosed prevalent disease. Indeed, the results of this study must be placed in a wider context about the benefits of screening for those with detectable disease. There is growing evidence for the benefit of intensive treatment of risk factors early in the course of the disease [33]. Results from ADDITION-Europe, a cluster-randomised trial of intensive, target-driven management of screen-detected individuals, showed that those identified and treated earlier had a mortality rate that was similar to that reported for people of the same age without diabetes in the general population in Denmark [18]. The possibility also remains that screening for diabetes and CVD risk factors followed by multifactorial treatment may have effects on microvascular and other morbidity not evaluated in this study. Furthermore, in a separate paper comparing the mortality rate and cardiovascular outcomes in individuals with incident diabetes in the screened group with those from the unscreened group, we show significant benefits for those diagnosed with diabetes in the screening practices [34]. Thus, while screening for diabetes and CVD risk factors may not have an impact at the population level, it appears to have benefits for the small subgroup found to have undiagnosed prevalent diabetes.

In conclusion, invitation to one round of screening for type 2 diabetes and cardiovascular risk assessment among middleaged adults in Danish general practice was not associated with a significant reduction in mortality rate or CVD events between 2001 and 2012. The benefits of population-based screening may be lower than expected and limited to individuals with detectable disease.

Acknowledgements We gratefully acknowledge the contribution of all participants, practice nurses and GPs in the ADDITION-Denmark study. With special thanks to M. Pedersen (Department of Public Health, University of Aarhus) for her help retrieving data from Statistics Denmark and to C. Boothby (MRC Epidemiology Unit, University of Cambridge) for her support with data coding.

Data availability The data used in this paper was a combination of data obtained from the ADDITION study and data from national Danish registers at Statistics Denmark (DST). The ADDITION study data were obtained after a written application to the data owner, A. Sandbæk (Institute of Public Health, Aarhus University, Aarhus, Denmark; annelli.sandbaek@ph.au.dk). Data from DST were made available following an application to DST (www.dst.dk/en/TilSalg/Forskningsservice). Data from ADDITION and DST were merged by DST and analyses were performed via a secure Virtual Private Network (VPN) connection. In accordance with the Danish Act on Processing of Personal Data, future interested researchers must perform the steps mentioned above to obtain access to the data.

Funding ADDITION-Denmark was supported by the National Health Services in the counties of Copenhagen, Aarhus, Ringkøbing, Ribe and South Jutland in Denmark, the Danish Council for Strategic Research, the Danish Research Foundation for General Practice, Novo Nordisk Foundation, the Danish Centre for Evaluation and Health Technology
Assessment, the diabetes fund of the National Board of Health, the Danish Medical Research Council, the Aarhus University Research Foundation. The trial has been supported by unrestricted grants from Novo Nordisk, Novo Nordisk Scandinavia, Novo Nordisk UK, ASTRA Denmark, Pfizer Denmark, GlaxoSmithKline Pharma Denmark, Servier Denmark and HemoCue Denmark.

Duality of interest RKS was supported by the European Foundation for the Study of Diabetes under an Albert Renold Travel grant to complete part of this work. DRW and RKS are supported by the Danish Diabetes Academy, which is funded by the Novo Nordisk Foundation. RKS is further supported by the Aarhus Institute of Advanced Studies. DRW reports receiving lecture fees from Novo Nordisk and Steno Diabetes Center. DRW and TL hold shares in Novo Nordisk. TL reports receiving a fee for attending an international board meeting for Astra Zeneca on early detection and treatment of diabetes in 2015. AS reports receiving lecture fees for providing continuing medical education to GPs. SJG's research programme is supported by Medical Research Council (MRC) Epidemiology Unit core funding (MC_UU_12015/4). SJG is a National Institute for Health Research (NIHR) Senior Investigator and member of the NIHR School for Primary Care Research. SJG receives an honorarium and reimbursement of travel expenses from Eli Lilly associated with membership of an independent data monitoring committee for a randomised trial of a medication to lower glucose. SJG received an honorarium from Janssen for speaking at an educational meeting in 2015. KB-J has no duality of interest associated with this manuscript.

Author contributions RKS and AS had full access to all of the data in the study and take responsibility for the accuracy of the data analysis. RKS and AS act as guarantors for this paper. AS, TL and KB-J designed the ADDITION-Denmark study and are principal investigators for the trial. SJG conceived the study question for this paper. SJG, TL, AS, DRW and RKS developed the study proposal. AS and RKS participated in the acquisition of the data from Statistics Denmark. RKS analysed the data and drafted the report. RKS, SJG, DRW, KB-J, TL and AS participated in the interpretation of the data, critical revision of the report for important intellectual content and gave final approval for this version to be published. RKS, KB-J, TL and AS provided administrative, technical and material support for the study.

Open Access This article is distributed under the terms of the Creative Commons Attribution 4.0 International License (http:// creativecommons.org/licenses/by/4.0/), which permits unrestricted use, distribution, and reproduction in any medium, provided you give appropriate credit to the original author(s) and the source, provide a link to the Creative Commons license, and indicate if changes were made.

\section{References}

1. Department of Health (2008) Putting prevention first. Vascular checks: risk assessment and management. Department of Health, London

2. Siu AL (2015) Screening for abnormal blood glucose and type 2 diabetes mellitus: U.S. preventive services task force recommendation statement. Ann Intern Med 163:861-868

3. Kuo HS, Chang HJ, Chou P, Teng L, Chen TH (1999) A Markov chain model to assess the efficacy of screening for non-insulin dependent diabetes mellitus (NIDDM). Int J Epidemiol 28:233-240

4. Chang HJ, Kuo HS, Tung TH, Chou P, Chen TH (2000) Evaluation of a population-based screening for type 2 diabetes: a communitybased screening project in Puli, Taiwan. Prev Med 31:396-402 
5. Kahn R, Alperin P, Eddy D et al (2010) Age at initiation and frequency of screening to detect type 2 diabetes: a cost-effectiveness analysis. Lancet 375:1365-1374

6. Schuetz CA, Alperin P, Guda S et al (2013) A standardized vascular disease health check in Europe: a cost-effectiveness analysis. PLoS One 8:e66454

7. Herman WH, Ye W, Griffin SJ et al (2015) Early detection and treatment of type 2 diabetes reduce cardiovascular morbidity and mortality: a simulation of the results of the Anglo-Danish-Dutch study of intensive treatment in people with screen-detected diabetes in primary care (ADDITION-Europe). Diabetes Care 38:14491455

8. Simmons RK, Echouffo-Tcheugui JB, Sharp SJ et al (2012) Screening for type 2 diabetes and population mortality over 10 years (ADDITION-Cambridge): a cluster-randomised controlled trial. Lancet 380:1741-1748

9. Jorgensen T, Jacobsen RK, Toft U, Aadahl M, Glumer C, Pisinger C (2014) Effect of screening and lifestyle counselling on incidence of ischaemic heart disease in general population: Inter99 randomised trial. BMJ 348:g3617

10. Krogsbøll LT, Jørgensen KJ, Grønhøj Larsen C, Gotzsche PC (2012) General health checks in adults for reducing morbidity and mortality from disease. Cochrane Database Syst Rev, Issue 10, Art. no.: CD009009. doi: 10.1002/14651858.CD009009.pub2

11. Blomstedt $Y$, Norberg M, Stenlund H et al (2015) Impact of a combined community and primary care prevention strategy on allcause and cardiovascular mortality: a cohort analysis based on 1 million person-years of follow-up in Vasterbotten County, Sweden, during 1990-2006. BMJ Open 5:e009651

12. Prasad V, Lenzer J, Newman DH (2016) Why cancer screening has never been shown to "save lives" and what we can do about it. BMJ 352:h6080

13. Lauritzen T, Griffin S, Borch-Johnsen K, Wareham NJ, Wolffenbuttel BH, Rutten G (2000) The ADDITION study: proposed trial of the cost-effectiveness of an intensive multifactorial intervention on morbidity and mortality among people with type 2 diabetes detected by screening. Int J Obes Relat Metab Disord 24(Suppl 3):S6-S11

14. Christensen JO, Sandbaek A, Lauritzen T, Borch-Johnsen K (2004) Population-based stepwise screening for unrecognised type 2 diabetes is ineffective in general practice despite reliable algorithms. Diabetologia 47:1566-1573

15. Glumer C, Carstensen B, Sandbaek A, Lauritzen T, Jorgensen T, Borch-Johnsen K (2004) A Danish diabetes risk score for targeted screening: the Inter99 study. Diabetes Care 27:727-733

16. Conroy RM, Pyorala K, Fitzgerald AP et al (2003) Estimation of ten-year risk of fatal cardiovascular disease in Europe: the SCORE project. Eur Heart J 24:987-1003

17. Alberti KG, Zimmet PZ (1998) Definition, diagnosis and classification of diabetes mellitus and its complications. Part 1: diagnosis and classification of diabetes mellitus provisional report of a WHO consultation. Diabet Med 15:539-553

18. Griffin SJ, Borch-Johnsen K, Davies MJ et al (2011) Effect of early intensive multifactorial therapy on 5-year cardiovascular outcomes in individuals with type 2 diabetes detected by screening (ADDITIONEurope): a cluster-randomised trial. Lancet 378:156-167

19. Dansk Selskab for Almen Medicin (1998) Forebyggelse af hjertesygdom i almen praksis - med særligt henblik på dyslipidæmi.
Updated 2002 and 2007. Copenhagen: Dansk Selskab for Almen Medicin [paper in Danish]

20. UNESCO (1997) International Standard Classification of Education 1997. United Nations Educational, Scientific and Cultural Organization, Paris

21. Huber PJ (1967) The behavior of maximum likelihood estimates under nonstandard conditions. Proceedings of the Fifth Berkeley Symposium on Mathematical Statistics and Probability 1: 221-233

22. Simmons RK, Rahman M, Jakes RW et al (2011) Effect of population screening for type 2 diabetes on mortality: long-term follow-up of the Ely cohort. Diabetologia 54:312-319

23. Sargeant LA, Simmons RK, Barling RS et al (2010) Who attends a UK diabetes screening programme? Findings from the ADDITION-Cambridge study. Diabet Med 27:995-1003

24. Schroder FH, Hugosson J, Roobol MJ et al (2009) Screening and prostate-cancer mortality in a randomized European study. N Engl J Med 360:1320-1328

25. Rasmussen SS, Johansen NB, Witte DR et al (2016) Incidence of register-based diabetes 10 years after a stepwise diabetes screening programme: the ADDITION-Denmark study. Diabetologia 59: 989-997

26. Spijkerman A, Griffin S, Dekker J, Nijpels G, Wareham NJ (2002) What is the risk of mortality for people who are screen positive in a diabetes screening programme but who do not have diabetes on biochemical testing? Diabetes screening programmes from a public health perspective. J Med Screen 9:187-190

27. Robson J, Dostal I, Sheikh A et al (2016) The NHS health check in England: an evaluation of the first 4 years. BMJ Open 6:e08840

28. Graversen L, Christensen B, Borch-Johnsen K, Lauritzen T, Sandbaek A (2011) Lipid-lowering drugs as primary prevention in general practice: do patients reach guideline goals and continue treatment? ADDITION Denmark. Scand J Prim Health Care 29: 216-221

29. Graversen L, Christensen B, Borch-Johnsen K, Lauritzen T, Sandbaek A (2010) General practitioners' adherence to guidelines on management of dyslipidaemia: ADDITION-Denmark. Scand J Prim Health Care 28:47-54

30. Simmons RK, Carlsen AH, Griffin SJ et al (2014) Variation in prescribing of lipid-lowering medication in primary care is associated with incidence of cardiovascular disease and all-cause mortality in people with screen-detected diabetes: findings from the ADDITION-Denmark trial. Diabet Med 31:1577-1585

31. Eborall H, Davies R, Kinmonth AL, Griffin S, Lawton J (2007) Patients' experiences of screening for type 2 diabetes: prospective qualitative study embedded in the ADDITION (Cambridge) randomised controlled trial. BMJ 335:490

32. Eborall HC, Griffin SJ, Prevost AT, Kinmonth AL, French DP, Sutton S (2007) Psychological impact of screening for type 2 diabetes: controlled trial and comparative study embedded in the ADDITION (Cambridge) randomised controlled trial. BMJ 335: 486

33. Holman RR, Paul SK, Bethel MA, Matthews DR, Neil HA (2008) 10-year follow-up of intensive glucose control in type 2 diabetes. New Engl J Med 359:1577-1589

34. Simmons RK, Griffin SJ, Lauritzen T, Sandbæk A (2017) Effect of screening for type 2 diabetes on risk of cardiovascular disease and mortality: a controlled trial among 139,075 individuals diagnosed with diabetes in Denmark between 2001 and 2009. Diabetologia. doi:10.1007/s00125-017-4299-y 